\title{
AESTHETIC PARADIGMS FOR AN URBAN ECOLOGY
}

Environmental aesthetics has become a matter of concern to many different groups in recent years--to conservationists, to legislators, reluctantly to industrialists, and indeed to the public at large. This interest seems to have a clear purpose. It is regarded as an effort, belated and desperate, to save the resources and beauties of our natural world from the possibility of complete and irrecoverable exploitation, and from the disfigurement and loss that must follow. It is an attempt to change the atmosphere from a toxic medium that is often impossible to escape back to one that is fresh and invigorating. It is a proposal to rebuild our cities before they become unredeemable wastelands of physical and social decay.

Yet if a concern for environmental quality is to result in more than a program for removing billboards, camouflaging junkyards, and replacing slums with tenements of the future, it must go beyond mere palliatives in the form of comforting images of prettiness, cleanliness, and order. A serious concern for environment should serve as a cue to both the artist and the aesthetician to develop images, concepts, and principles that will articulate and rationalize the convictions and the values that have given rise to these efforts, leading them toward goals that are at once richer and more substantive.

It may seem, however, as though doing this would require an act of philosophical creation ex nihilo, for philosophers have never devoted much attention to such questions, and with the exception of a few thinkers like Kant, Ruskin, and Santayana, have tended to ignore the aesthetics of nature altogether. Philosophical aesthetics, for the most part, has turned to nature for illustration and inspiration or as a model for emulation, but only rarely as an occasion for perceptual experience comparable in significance and profundity to the experience of art. 
Now while an aesthetics of nature may be a new problem for most philosophers, it involves a concern with the natural and ordinary in our surroundings which is not unusual for many contemporary artists. Some of the arts have moved in the last few decades towards an involvement with just [such] an interest by developing artistic forms such as assemblages, environments, Happenings, and earth sculpture that draw on ordinary objects, events, and surroundings. Many of the arts, however, have always handled features that bear directly on the experience of nature and the ordinary world. Both painting and sculpture, for example, employ perceptual dimensions that work by enlarging and refining natural experience rather than by substituting a different mode of experience for it. Sculptural space and volume are continuous with natural space and volume, and sculpture's shapes, textures, and lighting often have a direct source in the forms, surfaces, and light of natural objects, materials, and places. ${ }^{1}$ Painting also opens a range of space, light, and color that often extends beyond the picture frame. There is a continuity between the pictorial landscape and the actual one, not a relation between original and copy but a shared aspect, as when distance depicted by means of perspective begins at the eye of the viewer, with both picture and perceiver inhabiting the same perceptual space. In the still life, too, a way of looking is opened to us which we carry over to the common objects that surround us, and in the portrait we learn to see the people we have always looked at. Even when they develop in the direction of greater abstraction, these arts continue to act as models for experiencing the world which lies outside the frame and the museum. ${ }^{2}$ Much the same kinds of perceptual dimensions of space, color, line, form, composition and texture persist as outward appearances lose their resemblance to familiar objects. ${ }^{3}$

\footnotetext{
1 See Henry Moore, "The Sculptor's Aims," in Modern Artists on Art, ed. R.L. Herbert (Englewood Cliffs: Prentice-Hall, 1964).

2 See Piet Mondrian, "Plastic Art and Pure Plastic Art," in Modern Artists on Art, esp. pp. 127-130. "This consequence brings us, in a future perhaps remote, toward the end of art as a thing separated from our surrounding environment, which is the actual plastic reality. 'But this end is at the same time a new beginning., Art will not only continue but will realize itself more and more. By the unification of architecture, sculpture, and painting, a new plastic reality will be created. Painting and sculpture will not manifest themselves as separate objects, nor as 'moral art' which destroys architecture itself, nor as 'applied' art, but being purely constructive will aid the creation of a surrounding not merely utilitarian or rational but also pure and complete in its beauty."

3 These brief observations on the continuities between the arts and the ordinary world and their significance for aesthetics are intended to be suggestive rather than demonstrative, and clearly warrant extended development in their own right. To do so here would lead us into a digression that would be
} 
Unfortunately, however, we labor under a tradition which stresses the differences between the attitude we take toward art and the one we assume toward our "ordinary" human environment. Two things have contributed to establishing this. First there has been the long-standing influence of a cognitive standard for art, the demand that art adhere to the requirements of truth and knowledge, both in its content and in the way it is to be apprehended. Later there developed a search for artistic independence and for an identity that rendered art distinct from other kinds of objects and experiences. Such influences as these have given rise to the usual description of the aesthetic attitude as contemplative, passive, and disinterested, quite removed from the dynamic physical engagement which characterizes the way we usually react with our surroundings. ${ }^{4}$

It is precisely here that recent developments in the arts challenge this aesthetics of aloofness and bring art back into continuity with all objects and conditions in the world. Consider what they have done. In pop art, objets trouvés, and Happenings, the arts have plucked images, materials, and situations out of the commercial and industrial world of every day affairs and have held them before us, not in order to contemplate them disinterestedly, but to act upon and react to them. In optical art and kinetic sculpture the arts have disrupted the passive ease of contemplative appreciation by prodding us into active cooperation. Erotic themes have joined political ones to make the visual and dramatic arts occasions of involvement and not of detached observation. Music dance, and film have increasingly excite the somatic involvement that has always been present until we can no longer disregard it in any attempt to describe what happens.

Yet as we come to recognize the significance of the participatory response, we can look back at the traditional arts to find it present all along. Architecture, always a troublesome case because of its inability to divest itself of functional considerations and

more fascinating than essential to the main objective of this essay. I have treated this question at greater length in several other places. Se "Aesthetics and the Contemporary Arts,' Journal of Aesthetics and Art Criticism, XXIX, 2 (Winter 1970), 155-168; "Aesthetic Function," in Phenomenology and Natural Existence (Albany: SUNY Press, 1973), ed. D. Riepe. 
social utility, turns out to be not only a suggestive model for interpreting the fine arts but a portal through which the practical arts, conveniently de-classed by tradition, can finally enter the field of aesthetics. That same continuity between the creative activity, skill, and purpose of production and the completeness of the finished art object appears in painting, sculpture, and poetry no less than in architecture and design. Humanistic function, which integrates both creation, appreciation, and use into the matrix of people's needs, activities, and goals, now embraces all the arts. ${ }^{5}$ What is of particular importance, however, is that this new condition of art requires new aesthetic concepts to account for it. And what is more to our purpose here, this changed condition of art holds aesthetic implications for the broadest context of our experience--the human environment.

Perhaps the most striking condition, one that the new arts almost always insist on, is the continuity and likeness of the activities and objects of art with those of ordinary life. This takes many diverse forms, from the way artists readily employ industrial and commercial materials, images, and themes together with those of daily living, to the quantity, precision, and expendability, possible only through industrial production, becoming features of the production and consumption of art. In perception, this continuity takes the form of an engagement with the art object to an extent that refutes the traditional accounts of distance and contemplation. Such an engagement recalls the awe and danger inherent in the magical which characterizes primitive animism, and which perhaps has some connection with the sense of mystery and power which invariably grips us when we come under the spell of art. ${ }^{6}$ Joining with this continuity and engagement is the new dynamic character of art, shifting the deceptively static condition of art to a vital, almost disquietingly active role: from an object which moves before us, as in kinetic sculpture, which surrounds us, as in environments, which twists our eye in futile attempts to conform, as in optical art, which reflects our startled faces in mirrors and polished surfaces, to the walking, feeling, stimulating behavior with

\footnotetext{
See David Lowenthal, "The American Scene"

See my "Aesthetic Function."

See Ernst Fischer, The Necessity of Art (Hammondsworth: Penguin, 1963), pp.33-38, 156-169, 219-225.
} 
which the perceiver acts upon the object. ${ }^{7}$ Third and most inclusive is the pervasive functionalism which we now come to see, not as a narrow, barren utility, but rather more broadly as an active interchange of man and object. An object whose qualities and significance are continuous with all of our experience and an object which focuses on the immediacy of the human world, the work of art provides the fullest condition and the most complete model for living.

These three features of the new aesthetic--the continuity between art and life, the dynamic character of art, and the humanistic functionalism of the aesthetic act--suggest a conceptual framework that goes far beyond conventional limits, one which offers the possibility, not of aesthetic experience diluted past recognition, but rather a basis for opening the world to full perceptual vision whose implications are not only aesthetic but moral and political as well.

The broad nature of these concepts can help us apply them to more than conventional aesthetic situations. They are, in fact, especially suggestive in dealing with occasions that appear to exceed traditional limits and for which traditional accounts are not only of little help but actually misguiding. The environment, in particular, is one such situation, whether it be primarily natural or man-made. There is, for example, a sunrise or sunset where the horizon is unobstructed, the most spectacular light show ever observed. There is the medieval cathedral, a total physical and social environment that brings together not only most of the arts but engages all the senses as well. There is the sailing ship, that artifact which combines the most perfect functionalism with great beauty of object, and demands a complete engagement of the experiencer in an environment whose sensory and utilitarian features must be fully integrated. ${ }^{8}$ There is the circus, a highly charged world of fantasy and adventure which surrounds us with an environment thick with sound, sight, and movement, a dream world of the magical, the grotesque, the dangerous.

\footnotetext{
7 See my "Aesthetics and the Contemporary Arts," The Aesthetic Field (Springfield: C.C. Thomas, 1970), and Art and Engagement (Philadelphia: Temple University Press, 1991).

8 Horace Greenough, "Structure and Organization" and "American Architecture," in Form and Function (Berkeley and Los Angeles: University of California Press, 1966).
} 
There is yet another environment, the urban realm, to which this new aesthetic has a special appropriateness. The urban region is a setting of both total life and total art, a matrix within which all human experience may take place. It is the locus of the practical activities of work, of family, of education, of commerce, and of the predominantly aesthetic activities of art, culture, and sociality. These, moreover, are not always separable, and, as with the new arts, become most successful when most fully continuous and integrated with each other.

Let me, half playfully, half seriously, approach the urban environment from the vantage point of these new aesthetic ideas by developing the environmental situations that were just cited as paradigms for a developed urban aesthetic. For it appears to me that the experience of the circus, the cathedral, the sailing ship, and the sunset, while intriguing environments in their own right, represent in clear form dimensions of the experience of the city which are often not clearly recognized and which develop only fortuitously. More precisely articulated, they may serve as useful guides in cultivating an urban ecology to replace these forces of vulgarity and monotony that depress the modern city, and thus help transform it from a place where one's humanity is constantly threatened into a place where it is continually achieved and enlarged.

It was Horatio Greenough who, in the mid-nineteenth century, gloried in the design of the sailing ship as a model for architecture.

Observe a ship at sea! Mark the majestic form of her hull as she rushes through the water, observe the graceful bend of her body, the gentle transition from round to flat, the grasp of her heel, the leap of her bows, the symmetry and rich tracery of her spars and rigging, and those grand wind muscles, her sails.... Here is the result of the study of man upon the great deep, where Nature spake of the laws of building, not in the feather and in the flower, but in wind and waves, and he 
bent all his mind to hear and to obey. ${ }^{9}$

Yet there is more to the sailing ship than its physical design, for a ship requires not only a architect but a helmsman, and not only a helmsman but a captain, navigator, and seaman. That is to say, in the functional environment of the sailing ship there is a synthesis of the mechanical forces of hull and water, wind and sails and rigging under the manual guidance of the sailor. To accomplish this properly the entire sensory and physical environment must be joined together. Not only must the curvilinear hull withstand the pressures of the liquid medium through which it presses; it must also be designed to penetrate the water, to cut through waves and keep its track steady, and to forge ahead under a wide range of sea conditions from near calm to fresh gale. But the hull is only one side of the parallelogram of forces, for wind provides the drive which powers the hull, and the placement and shape of sails and the spars and rigging which control them must also be adapted to the range of prevailing conditions. Thus emerges an endless variety of hull types and sail plans, from ocean clipper to coasting schooner, from the fishing craft of bays and banks to cruising and racing yachts, where indigenous designs reflect the ingenuity of an application to local conditions.

Yet it is a necessity for the professional sailor and a delight for the yachtsman to enter bodily into the functional process, controlling the movements of his craft in an act of skill that is an act of beauty. Here one must join his sensory being to the clean efficiency of the sailing ship in a fusion that allows no division to intrude. Always watchful of sky and horizon, eye, ear, and skin record every shift in wind, every variation in its strength. The murmur, gurgle, slap, crash of water are signs, too, of what is happening as the vessel presses along. Even the smell of sea air and fog and the taste of salt spray add to the quality of the experience. Yet a sensory alertness for signs of changing conditions must join with the physical control of the vessel. The feel of the wheel's or tiller's pressure is a constant guide to the ship's course and an indicator of the forces acting on its passage through the water, and the never-ending adjustment of the sails by a web of lines, each with its specific purpose, reflects the

${ }^{9}$ Form and Function, pp.60-61. 
striving for perfect efficiency in conditions that are constantly shifting. Moreover, the penumbra of past and future time surrounds the acuteness of the perception of the present, for the sailor is endlessly alert to signs of change in clouds, wind, water surface, and in the color of horizon and sea, and he completes and tempers his observations and responses with he resonance of past experience. To this perceptual synthesis the seasoned sailor further joins a range of lived meanings--of weather lore, navigation, and seamanship, for it is from this endless body of nautical knowledge that the sensory environment acquires it significance.

Thus a synesthetic experience develops, with movement of body and boat combining in a power wrought of a harmony of purpose. Here is a total environment, a functional setting fusing the mechanical and the organic in an intensely perceptual world.

There are times when we can sense this experiential unity, even as observers. Just as we may see a fine old Maine farmhouse settled on a hillside as an integral part of the environment and not as an alien element in a natural field, so we may see a sailboat in a bay as belonging to that setting rather than intruding on it. ${ }^{10}$ Perhaps something of the same sense of incompleteness or, even more, of the forlorn that strikes us when we see a boat out of the water affects us in seeing a harbor empty of all craft. This can be carried still further, for had it not been for the sailing ship, the ocean would not exist for us. There would be only the shore, which we would then regard only as the limit of the land rather than the boundary of the sea. ${ }^{11}$ Yet in this fusion of sailor, sailing ship, water, wind, and sky a total environment is created, a functional setting that is fully humanized. Such an environment displays in a remarkable way Dewey's combination of the "relation of means and consequence, process and product,

10 One would do well to be cautious here, however. We may well be mistaken about what we, as observers from outside, regard as the experiential units of an environment, especially when we cannot participate in it as part of the social milieu in which it has meaning and value. See Raymond Williams, the Country and the City (London: Chatto and Windus, 1973).

11 We may marvel at the isolation, perhaps the desolation, of the ocean ocean, but we can never actually encounter the truly open ocean, for we are always present as observers. In true Berleleyan fashion, there is no perceptual environment from which people are absent, and conceptualizing about such a place never deals with the actual environment as it is experienced but only through our 
instrumental and consummatory. Any activity that is simultaneously both, rather than in alternative and displacement, is art." ${ }^{12}$

Perhaps nothing could be more different from a sailing ship than a circus. Here there appears no sign of utility at all but rather a world of fantasy, a spectacle we consign to children and child-like occasions. Despite its air of transparent make believe, however, the circus holds a peculiar fascination for us, for the realm of fantasy that it creates awes and shocks us at the same time that it evokes our admiration and excites our amusement. There is a strange quality that grips us as soon as we enter a circus grounds. Even though the circus turns reality upside down with forms that are grotesquely exaggerated, it carries along with it at the same time an undercurrent of truthfulness not unlike the fictional truth of literature, for we are cast into a topsy-turvy world where men are either sub-human or superhuman, either fools or gods, and where only the animals exhibit distinctively human characteristics.

Take the superhumans of the circus. Like Greek Mercuries the aerialists swoop through space, their flying bodies functioning with perfect grace and uncanny coordination, and we gasp our admiration at this transcendence of man's earthbound being. There is perfection of from, too, in the bareback and elephant riders. With remarkable balance they defy gravity, standing poised and beautiful, high above those who move with slow feet mired in the ground. As the trapeze artists and riders represent grace, speed, and etheriality, the lion tamer awes us with his fearlessness and courage. Standing calm and muscular alone in a cage with a pride of lions, he intimidates the regal creatures by voice and whip. With chest bared to the brutal face of danger, the lion tamer asserts his power, surpassing the beasts and reducing them to meek obedience. In similar ways the jugglers exhibit a magical dexterity and the acrobats surpassing strength and agility. 
To these gods of the circus are opposed those sub-humans, the clowns. Simpletons, the whiteface clowns indulge $\mathrm{n}$ the grossest miscalculations, slipping, stumbling, tripping, falling over themselves into all those errors of inference and judgment we believe we so easily avoid. They are the boobs, the stooges, the fools of the world, parodying our own inanities with embarrassing accuracy, just as the clowns of the entertainment world like the Marx Brothers and Woody Allen have always done. Like us, they too have their delusions of grandeur. There is always one who will attempt to emulate the circus gods by walking the tightrope. Epitomizing that human combination of foolish pride and blind foolishness, he re-enacts a version of the Fall (sic), and is saved from a suicidal plunge by what seems to be a combination of bravura and luck, but what could only be divine mercy. In contrast to the white faces, the august or grotesque clowns are the mischievous ones, disrupting the attempts of the whitefaces to scale the heights of the simple, or exaggerating human foibles, reactions, expressions, or feelings. Lastly there are the character clowns, who parody certain human types like cops, tramps, teachers, or relational pairs of people so effectively that we find ourselves laughing at ourselves.

In contrast to the brilliant feats of the circus gods and the frenetic bumbling of the clowns, in the world of the big top it is oddly enough the animals who are "human." It is they who reflect a certain calm and dignity in their actions. The elephants move with lumbering obedience, sitting and standing as the occasion requires; the tigers lope with careful regularity through hoops and calmly seat themselves on stools; the dogs, dressed in children's clothes. walk, run, or engage in anthropoid exchanges, or, like children on display, obediently show themselves off; the horses trot in perfect circles: all exhibit those characteristics of order, rationality and control which, with blithe presumption, we assign to mankind alone. Or the animals reflect the sharp deviousness that is another side of human behavior: dogs, for example, are often paired with clowns, and it is they who outwit their self-styled "masters," unperturbed by the antics of those creatures at the other end of the leash. 
Yet there is an obverse side to the circus. This environment, with its accompaniment of barkers, hawkers, side shows, calliope, crowds, and the jostling strange exhilaration that is part of the festive scene, also awakens in us undercurrents of response that are strangely primeval. Here is one of the few places in the modern world in which the primoridal is allowed, and we can indulge our fascination with the wondrous, the weird, the grotesque, the terrifying without incurring disapproval. For along with the excitement brought on by the fantastic spectacle of dazzling costumes and incredible performances, there is the fascination with danger and the terror that it excites that draws many to the circus grounds. The feats of the stars are not only brilliant; they are breathtaking, deliberately designed to terrify the audience. The German expressionist film, the Cabinet of Dr. Caligari, is a classic illustration of this spell, an intermingling of dream, delusion, madness, terror, sorcery, and death that reads out motifs inherent in the circus scene. The circus, in fact, exemplifies a quality of crowd madness that is shared in part by certain other public spectacles, such as parades, gladiatorial combats (sublimated into boxing, wrestling, football, soccer, the roller derby, hockey, and the like, where the embers of violence are always present and sometimes burst into flame), public executions, and even first and riots. To these clowns of the world provide a humorous but weak comparison.

To move from the world of the circus to the spiritual reaches of the Goth cathedral requires another rapid change of scene. Yet like a circus, the cathedral has its roots in a deep well of experience that lies far beneath the regularity and order of public life. In contrast to the functional environment of the sailing ship and the fantasy environment of the circus, the cathedral evokes what may be called a metaphysical environment, a setting which offers communion with Being in its physical, social, and spiritual manifestations.

For us who are products of the secular, technological culture of post-medieval Europe and its ensuing fragmentation of experience into discrete and uncommunicating segments, it is difficult to capture the awareness of that homogeneity of culture for which the medieval cathedral stood, at the same time as both symbol and the 
embodiment. Here is a monument, towering, impressive, overpowering. And yet, as Philip Johnson has observed, "Monumentality is strangely functional." ${ }^{13}$ The cathedral had a place in social consciousness, but it had a more immediate personal significance. Even without the surplice of religious conviction, we can sense the meanings, the human significance which the cathedral houses when we pass through its portals. for the cathedral is a sacred place, one in which we stand exposed and vulnerable in spiritual nakedness, and where everything contributes toward achieving that effect.

Like a monument the Gothic cathedral st retches high above the rooftops that surround it. Central, elevated, it is rarely out of sight and never forgotten. Whoever has lived by a mountain knows the persistent presence that it has in one;s awareness. You always stand in its shadow. You know the mountain is there even when it is not in view. When one goes out of doors, the mountain is the persistent focal point of one's wandering gaze: you look to it as to the sun to know the condition of the world. The Gothic cathedral is a man-made mountain, but it is a peak one climbs inside as well as out, spiritually as well as bodily.

Within, the cathedral is not just an interior space but a total environment. It is indeed a setting that engages all the senses, leaving no part of the believer unengaged. In a striking way, the cathedral is the original multi-media environment. Visually it surrounds one with dusky spaces, some broad and open, others low and shrouded in gloom, penetrated by colored shafts of sunlight, or glowing with halos of candle illumination. The richly jewelled windows, the profusion of paintings and sculpture, carved altarpieces, confessionals, and other works of fine art and craft convey a glimpse of the Heavenly City. Touch also enters, not only as the concomitant of sight but directly in its own right, from the rough grain of the pews grasped by many hands to the unevenness of the stone floors worn down by many feet, and even, as with Michelangelo's Pieta, contours smoothed by generations of lips. The live acoustics amplify the chanting voices, the singing choir, and the richly varied tones of the

13 Philip Johnson, "Why We Want Our Cities Ugly," in The Fitness of Man's Environment, Smithsonian Annual II (New York: Harper \& Row, 1968), p.157. 
organ--the only instrument capable of matching in the range and volume of its sounds the great depths of the cathedral's inner spaces. Even taste and smell are engaged by the bread and wine of communion and the lingering scent of incense, while the ornate ritual brings all these together in extravagant theater.

Yet not only does the cathedral create a sensory environment; it is at the same time a repository of spiritual meanings. The cathedral is at once a sanctuary, a mausoleum, a repository, a house of prayer, a sacred place where one encounters meanings that cannot be uttered and a God who cannot be known. Here are stored centuries of human aspirations and human tragedies constantly renewed by fresh supplicants, and we have communion with them all when we step inside.

This, then, is an edifice which totally envelops a person; we become like Victor Hugo's Quasimodo, enclosed in a cathedral which is our home, our country, our universe. ${ }^{14}$ We are caught up in a realm of mystery and miracle, suffused with meanings which transcend our understanding but not our experience. Here is a world which encloses us in a higher condition and greater significance

than our own, when for a time we go through ourselves to reach beyond and approach the glorious realm of heaven. In the range of its power and the breadth of its human significance, the Gothic cathedral is one of the most remarkable creations of mankind.

Let me speak finally (and more briefly) about the last of this series of environments: the sunset. In a sense the communion with Being of the metaphysical

\footnotetext{
14 For Quasimodo the cathedral had been successively "egg, nest, house, country and universe....One might almost say that he had espoused its form the way a snail does the form of its shell. It was his home, his hole, his envelope.... He adhered to it, as it were, like a turtle to its carapace. This rugged cathedral was his armor....It is useless to warn the reader not to take literally the figures of speech that I am obliged to use here to express the strange, symmetrical, immediate, almost consubstantial flexibility of a man and an edifice." Notre-Dame de Paris, Bk. IV, § 3.
} 
environment of the cathedral leads easily to the cosmic environment of the sunset. In fact, there is much they both have in common.

The sunset envelops us in the broadest environment possible, one that employs planetary motion and celestial time to produce a setting that engenders feelings of wonder and awe. Like the sunrise, its complement but not its precise symmetrical opposite, the sunset draws us into an environment of cosmic dimensions. Even though we understand quite well the reason for what occurs, there is nonetheless something awesome in observing it happen. This is made not less impressive but more so in this age of space travel, for we have acquired visual impressions of the movement of the moon and the earth, so that when we watch a sunset we can sense ourselves participating in that same act.

Like the cathedral, the sunset creates for us great reaches of space. It is no mere custom that leads us to seek a vantage point with an unobstructed view to observe the setting sun. And the spectacle includes not only the western horizon but the darkening eastern one and the clouds spread out overhead as well. Here is a monumental light show: With grand inevitability the light changes direction and the colors tone, moving from gold to rose to lavender to purple-gray to a steely gleam as the illumination shifts from a source above the horizon to one below and the night sky emerges. Again like the cathedral, there is an awesome hush of nature as well as humans that accompanies the inevitable workings of this celestial event. We stand in the presence of an act that has suffused all life from its bare emergence, and which every creature, human and proto-human, has witnessed from the beginning of consciousness. Here we join eons of time, sidereal space, cosmic motion. The presence of God can awe us; the presence of the universe overwhelms us.

Let us step back from this attempt to evoke something of the experience of these 
various environments to reflect on our first concern, the city. I should like to explore some ways in which each of these settings of human experience--the functional environment of the sailing ship, the fantasy of the circus, the metaphysical dimension of the cathedral, and the cosmic one of the sunset--has a certain suggestiveness for our attempt to examine urban ecology and experience. Each, indeed, stands as a paradigm for a dimension of the city which may be overlooked in the stress of the telic activities, confusions, pressures, tensions, and dangers that so often seem to dominate the urban condition. And each, in illuminating dimensions of the urban environment that often go unrecognized, can be used to generate critical measurements for a more fully developed urban aesthetic.

It is no longer unusual to regard the city as a functional environment. Yet function must include far more than practical expedience; we must introduce factors of movement, time, and perception into discussions that are often confined to the spatial and handled with the impersonality accorded problems in social engineering. A city is not just an agglomeration of objects in a particular place; it is a setting for human beings to carry on social activities at a certain level of density and a certain order of complexity. Thus the urban environment is a process, not a stasis. It generates an intricate combination of parallel and cross movements: a transportation network of pedestrians and of vehicles for personal mobility, such as bicycles, motorcycles, automobiles, buses, streetcars, subways, and ferries; a distribution network of trucks, trains, ships; a communication network of mail delivery, radio, television, newspapers, and magazines; an educational and cultural network of schools, libraries, concert halls, museums, art galleries; a dispensing network of stores and shops; a service network of repair centers, utilities, sewage system, and garbage collection. Further, the city is the setting for a multiplicity of human activities: productive, domestic, recreational, cultural.

Moreover, the city as a functional environment cannot be understood without recognizing the importance of time in its internal dynamic. Time coordinates the daily patterns of movement to and from work, school, shopping; the weekly cycle of work and leisure; and the seasonal one of residence, recreation, and travel. To these must be 
added historical time, the remembrance of times past in the uses that spring from earlier inhabitants--of Indian trails metamorphosed into paved thoroughfares, pagan temples transformed into Christian churches and later, perhaps, into museums or civic buildings. Future time, too, appears in the proposals for change embodied in master plans and in the reports of planning commissions--the continual process of rebuilding, reorganizing, and reshaping the urban environment. ${ }^{15}$

Even more, the functional model of the sailing ship reminds us of the central place of man as a concrete referent in developing the structures and relationships of an environment. This has long been recognized in attempts to derive architectural, landscape, and urban proportions from multiples of the dimensions of the human figure, attempts which range from Vitruvian man, through Alberti, to the Modular of Le Corbusier. Function should reflect human needs, abilities, and capacities for experience, and that is why urban design must in some manner respond to humanize, providing conditions for man's intimacy as well as for his glory. In the final analysis, urban design is domestic planning, and to be successful in providing a place that is also a home, it should complement and complete people, not dwarf, compress, or submerge them.

What is critical for achieving an urban environment of human proportions is our ability to determine and control the conditions that shape the perceptual patterns through which we carry on the life of the city. Thus in addition to structural dimensions that respond to the demands of the human form, the environment must work as a sensory one. For this reason urban design cannot be confined to the arrangement of objects but rather must be used to create sequences of experience. This can take many forms, one of which is what Kevin Lynch calls "imageability" or "legibility," those visual traits by which a city person can maintain the awareness of his position in the urban complex and find his way through it. Thus an imageable city is one whose paths, nodes, districts, boundaries, and landmarks are readily apparent and easily

15 See Kevin Lynch, What Time Is This Place? (Cambridge: M.I.T. Press, 1972). 
recognizable. ${ }^{16}$ Yet the fashioning of a sensory environment must go beyond an ordering of visual experiences to include others to which American culture is strangely insensitive: auditory stimuli that are more than the drone of traffic and the roar of machinery; tactile perceptions such as the surface textures of roads, walks, and façades; and olfactory sensations, noticed not as evidence of decay, fuel combustion, or manufacturing, but as appealing signs of the character of districts such as waterfront, market, restaurant, and park. Moreover, all the senses combine in the temporal progression of perception in concrete situations, as we drive along a street, walk through a park, stroll down a shopping plaza, sit in a square, or gaze out over the city from an observation tower. It is in the shaping of experience that is at once both instrumental and intrinsic that planning must see its role.

Thus a full range of sensory cues can serve to direct human activities, enabling us to move with comfort and security, as well as with interest and excitement through an urban setting that is shaped to a model of humanistic function. It then becomes clear that for an urban environment to function as a human one, it must succeed as a setting for experience, facilitating patterns of movement by determining the arrangement of things as they will be encountered in our perception. This does not only enable the city to work more effectively; it also enhances common symbols, meanings, and memories, provides emotional security, and helps make possible that social condition by which, as Aristotle observed long ago, many becomes fully human. ${ }^{17}$

\section{Arnold Berleant}

16 Kevin Lynch, the Image of the City (Cambridge: M.I.T. Press, 1960). This entire book is an insightful development of this experiential aspect of the urban environment.

17 Aristotle, Politics, Bk.I, Ch.2. 